\title{
A MODELING STUDY TO EVALUATE THE QUALITY OF WOOD SURFACE
}

\author{
Ender Hazir ${ }^{1, \wedge}$, Kücük Huseyin Koc ${ }^{1}$
}

\begin{abstract}
The goal of this study was to develop a model to predict sanding conditions of different type of materials such as Lebnon cedar (Cedrus libani) and European Black pine (Pinus nigra). Specimens were prepared using different values of grit size, cutting speed, feed rate, and sanding direction. Surface quality values of specimens were measured employing a laser- based robotic measurement system and stylus type measurement equipment. Full factorial design based Analysis of Variance was applied to determine the effective factors. These factors were used to develop the Artificial Neural Networks models for two different measurement systems. The MATLAB Neural Network Toolbox was used to predict the Artificial Neural Networks models. According to the results, the Artificial Neural Networks models were performed using Mean Absolute Percentage Error and R-square values. Mean Absolute Percentage Error values for laser and stylus equipment were found as 2,405 \% and 3,766 \%, respectively. R-square values were determined as $96,2 \%$ and $92,7 \%$ for laser and stylus measurement equipment, respectively. These results showed that the proposed models can be successfully used to predict the surface roughness values.
\end{abstract}

Keywords: Artificial neural network, laser measurement, stylus measurement, surface quality, wood sanding process.

\section{INTRODUCTION}

Sanding process is applied in different wood manufacturing applications. In furniture industry, this process presents some advantages such as low surface roughness, high productivity, appearance of wood products and high wood coating performance (Richter et. al 1995, Cool and Hernandez 2011, Scrinzi et al. 2011, Landry and Blanchet 2012, Hiziroglu et al. 2014, Gurau et al. 2015, Ugulino and Hernandez 2016, Sogutlu et al. 2016). Therefore, the surface roughness is the major indicator of wood surface quality. It is mainly a result of various controllable or uncontrollable sanding parameters. Anatomical structure, hardness, density, annual ring variation, cell structure early-late wood ratio are uncontrollable variables, while the sanding parameters such as feed rate, cutting speed, grit size, pressure, depth of cut, sandpaper type and cutting direction are controllable variables (Tan et al. 2012, Gurau et al. 2013, Magoss 2015, Ramananantoandro et al. 2017).

There are different roughness measuring techniques such as pneumatic, laser and light scattering techniques to determine the surface quality of wood and wood products (Hiziroglu and Suziki 2007, Hazir 2013, Zhong et al. 2013). Stylus type profilometer is commonly applied due to its usefulness and advantage in obtaining accurate numerical results (Sandak and Tanaka 2003, Hiziroglu et al. 2014). Laser measurement system provides crucial advantages such as measuring the complex surface structures with non-contact equipment, decreasing the time consumption, gathering more data from

${ }^{1}$ Faculty of Forestry, Department of Forest Industry Engineering, Istanbul University, Istanbul, Turkey.

"Corresponding author: ender.hazir@istanbul.edu.tr

Received: 08.12.2017 Accepted: 27.05.2018 
the surfaces in a short time and obtaining online measurements in the real production process (Sandak and Tanaka 2003, Koc et al. 2017). The full factorial design is a powerful technique to determine the significant factors. It involves all possible combinations between input and output variables. Therefore, this design has been widely used in various engineering applications.

In the recent years, artificial intelligence algorithms such as Artificial Neural Network (ANN), Genetic Algorithm (GA), Fuzzy Logic (FL) and Particle Swarm Optimization (PSO) have applied to different engineering problems (Ozsahin and Aydin 2014, Mahes et al. 2015, Jain and Raj 2017).

Carrano et al. (2002) investigated sanding process of hard maple, white oak and eastern white pine as function of spindle speed, feed rate, depth of cut, grit size, tooling resilience and grain orientation. The results showed the grit size, tooling resilience and grain orientation were significant for all species. The feed rate was found as a significant factor for white oak and eastern white pine. Zhong et al. (2013) evaluated surface quality using stylus type profilometer and 3D image analyzer different wood materials such as particle board, medium density fiberboard, plywood and ten different solid wood. According to the results, these methods can be successfully applied to determine the surface quality. Tiryaki et al. (2014) modeled planing and sanding process of Spruce and Beech wood as function of spindle speed, cutting depth, feed rate, number of cutter, wood zone and grain size of abrasive. The results indicated the surface roughness decreased with increasing the grit number and number of the cutter. It was shown that ANN method can also be used successfully for modeling of surface roughness. A study was carried out by Laina et al. (2017) investigated sanding process of beech, oak and pine the function of grain direction, wood hardness and machining conditions such as planing and sanding process. The results showed the surface roughness was decreased from 60 to 180 grit size. Hardness was found as a significant factor for wood surface roughness. Hazir et al. (2017) developed a mathematical model to evaluate optimum sanding conditions of European black pine (Pinus nigra). Samples were sanded using different grit sizes, feed rates, cutting speeds and depths of cut. Response surface methodology (RSM) was used to determine the optimum parameters values.

The objective of this study was to develop a model to predict sanding conditions using ANN of two different wood species such as Lebnon cedar (Cedrus libani A.Rich) and European Black pine (Pinus nigra Arnold) for two different measurement equipment, namely laser and stylus.

\section{MATERIALS AND METHODS}

Lebnon cedar (Cedrus libani A.Rich) and European Black pine (Pinus nigra Arnold) species are extensively used in the furniture industry. The samples were prepared with the dimension of $200 \mathrm{~mm}$ x $100 \mathrm{~mm}$ x $30 \mathrm{~mm}$ for each test. Samples were conditioned in a climate room having a temperature of $20^{\circ} \mathrm{C}$ and relative humidity of $65 \%$ until they reach a moisture content of $10 \pm 1 \%$. The density of Lebnon cedar and Black pine was found as $570 \mathrm{~kg} / \mathrm{m}^{3}$ and $680 \mathrm{~kg} / \mathrm{m}^{3}$, respectively. The samples were processed with wide-belt sanding machine equipped with open coat aluminum oxide abrasive paper.

\section{Evaluation of wood surface quality}

In this study, wood surface quality was determined by using two different methods. (1) Laser-based system was employed to evaluate the surface quality. Cartesian robot integrated with laser sensor was used to gather data for evaluating the surface quality (Figure 1a). In order to determine the surface quality with the laser sensor, the robot was gathered with 500 data every $7 \mathrm{~mm}$ movement and the average values were calculated. Laser sensor was used to measure the wood surface for determining the various sanding parameters. The robot was controlled in $\mathrm{X}$ and $\mathrm{Y}$ axis for evaluating the wood surface quality. The laser sensor gave 500 measurements and the results were transferred into the MATLAB program.

(2) Another measurement equipment for determining the surface roughness values of machined wood material was the Taylor-Hobsan Suftronic type equipment (Figure 1b). This device is a stylus- 
based portable profilometer, equipped with a diamond stylus with a $5 \mu \mathrm{m}$ radius $12,5 \mathrm{~mm}$ length of measurement $2,5 \mathrm{~mm}$ length of sampling, $15 \mathrm{~mm}$ travel of stylus and $90^{\circ}$ contact angle running at a speed of $0,5 \mathrm{~mm} / \mathrm{s}$. were taken from sample surfaces. With reference to ISO 4287:1997, average roughness $\left(R_{a}\right)$ and mean peak to valley height $\left(R_{z}\right)$ are admitted as roughness parameters. In this study, $R_{a}$ parameter was selected to evaluate the surface roughness of the samples.

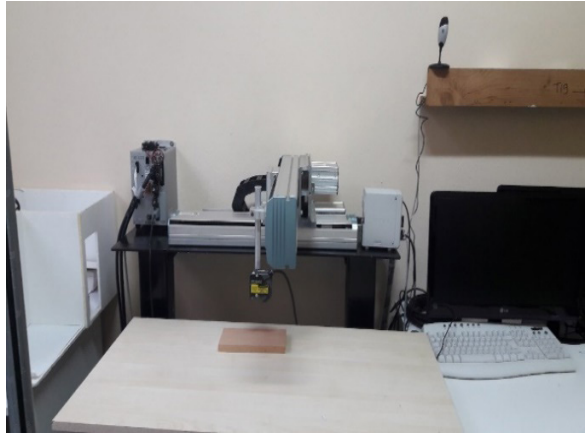

(a)

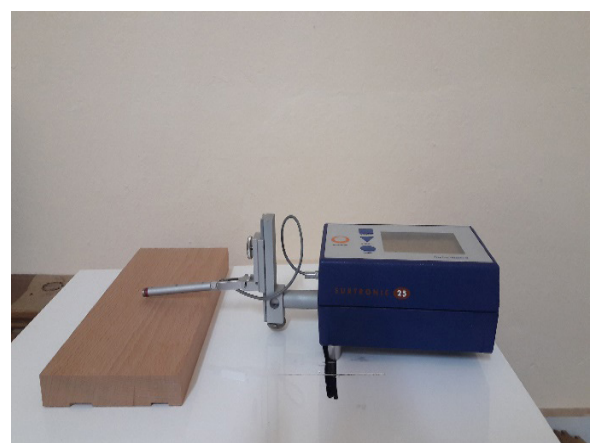

(b)

Figure 1. (a) Laser-based measurement system (b) stylus-based measurement equipment.

\section{Statistical design of experiment}

The statistical analysis was performed using Minitab software package 17. The full factorial experimental design was used to obtain the results. This design is one of the most important methods to investigate two or more parameters (Montgomery 1997). ANOVA was applied to experimental data in order to determine effective factors for both laser and stylus type equipment. Each independent variable had two and three levels which were coded as $(-1),(0)$ and $(+1)$. The low (-1), medium (0) and high $(+1)$ levels are given in (Table 1).

Table 1. Sanding procedure parameters and levels.

\begin{tabular}{|c|c|c|c|c|c|}
\hline Symbol & Parameters & Unit & Level (-1) & Level (0) & Level (+1) \\
\hline & & & & & \\
\hline A & Material type & - & Black pine & Lebnon cedar & - \\
\hline B & Cutting speed & $\mathrm{m} / \mathrm{sec}$. & 12 & 20 & 28 \\
\hline C & Feed rate & $\mathrm{m} / \mathrm{min}$. & 6 & 10 & 14 \\
\hline D & Grit size & - & 100 & 150 & 180 \\
\hline E & Sanding direction & - & Parallel & Orthogonal & - \\
\hline
\end{tabular}

\section{Artificial neural networks (ANN)}

Artificial neural networks (ANN) are developed with inspiration from information processing model of the biological neural system of the human brain. It is used non-linear and linear model for prediction and optimization of the data. ANNs are applied for engineering applications such as pattern recognition, forecasting and data processing (Karazi et al. 2009). This model consists of inputs, which are multiplied by weights. These weights are computed using mathematical function determining the activation of the neuron. This model learns the correlation between the input and output factors by using recorded data. An ANN system depends on neurons connected with the number of weighted links. Every piece of information is transferred to other neurons. Artificial neural network structure is given in (Figure 2). 


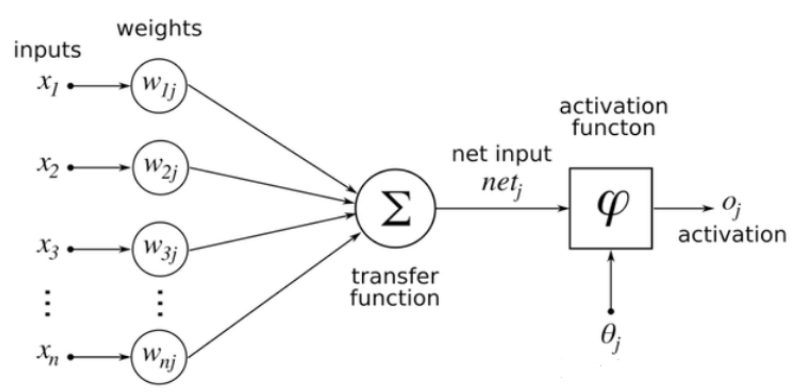

Figure 2. Artificial neural network structure.

An ANN is performed by using transfer function type, training algorithm, training and testing data size and values of weights and biases. This algorithm is formulated in Equation 1 and Equation 2:

$$
\begin{array}{r}
\text { net }_{j}=\sum_{i=1}^{n} X_{i} W_{j}-\theta_{j} \\
y_{i}=f\left(\text { net }_{j}\right)=\frac{1}{1+e^{- \text {net }_{j}}}
\end{array}
$$

Where the terms of $n t_{\mathrm{j}}, w_{i j}, j, x_{i}, \theta_{j}$ and $y_{i}$ are sums of information, weight factors, neuron, layer information, bias of the layer and output values, respectively. In this study, a feedforward and backpropagation multilayer ANN was carried out predicting the wood surface roughness for two different measurement systems. Moreover, the hyperbolic sigmoid function (tansig) and the linear transfer function were selected as transfer function. Levenberg-Marquardt algorithm (trainlm) was applied as training algorithm and gradient descent with a momentum back-propagation algorithm (traingdm) was selected as learning rule. To evaluate the ANN model, Mean Squared Error (MSE), Mean Absolute Percentage Error (MAPE) and R-square $\left(\mathrm{R}^{2}\right)$ values were used to test the accuracy of the results. MAPE, MSE and $\mathrm{R}^{2}$ were computed with Equation 3, Equation 4 and Equation 5. The terms of $A_{t}, F_{t}$ and $F_{t}$ indicate the actual, predicted and the average of predicted values, respectively.

$$
\begin{array}{r}
M A P E=\frac{\sum_{t=1}^{n}\left|\frac{A_{t}-F_{t}}{A_{t}}\right|}{n} \times 100 \\
M S E=\frac{\sum_{t=1}^{n}\left(A_{t}-F_{t}\right)^{2}}{n} \\
R^{2}=1-\frac{\sum_{t=1}^{n}\left(A_{t}-F_{t}\right)^{2}}{\sum_{t=1}^{n}\left(A_{t}-\overline{F_{t}}\right)^{2}}
\end{array}
$$


In order to determine an equal contribution of each variable, these parameters were normalized using Equation 6. This process ensured the best generalization performance of ANN model. Training, testing and validation data were normalized by carrying out their minimum and maximum values within the range of $[-1,1]$. The model parameters were normalized by computing Equation 6 .

$$
X_{\text {norm }}=2 \times \frac{X-X_{\min }}{X_{\max }-X_{\min }}-1
$$

The terms of $X_{n o r m}, X_{\max }$ and $X_{\min }$ are normalized value of a variable $X$, maximum and minimum values of $X$, respectively.

\section{RESULTS AND ANALYSIS}

The experiment consisted of five factors and one replicate, making a total of 108 runs ( $3 \times 3 \times 3 \times 2 \times 2$ ). (Table 2 ) shows the experimental parameters and their recoded laser and stylus measurement roughness values. In both measurement methods, the average roughness values were calculated by taking measurements from three different points on the wooden surface.

Table 2. Experimental parameters and the recorded roughness values of laser and stylus measurement.

\begin{tabular}{|c|c|c|c|c|c|c|c|}
\hline \multirow{4}{*}{$\begin{array}{l}\text { A } \\
\text { BP }\end{array}$} & \multirow{4}{*}{$\begin{array}{l}\text { B } \\
12\end{array}$} & \multirow{3}{*}{$C$} & \multirow[b]{3}{*}{$\mathbf{D}$} & \multicolumn{2}{|c|}{ Sanding Direction (E) } & \multicolumn{2}{|c|}{ Sanding Direction (E) } \\
\hline & & & & Parallel & Orthogonal & Parallel & Orthogonal \\
\hline & & & & \multicolumn{2}{|c|}{ Ra(um)-Stylus } & \multicolumn{2}{|c|}{ Ra(um)-Laser } \\
\hline & & 10 & 150 & 7,46 & 6,83 & 16,43 & 16,22 \\
\hline LC & 20 & 10 & 100 & 6,42 & 6,53 & 15,32 & 15,51 \\
\hline BP & 28 & 10 & 180 & 5,86 & 6,24 & 13,78 & 14,76 \\
\hline LC & 12 & 10 & 150 & 7,86 & 7,03 & 18,63 & 16,81 \\
\hline BP & 20 & 10 & 100 & 6,76 & 6,52 & 16,05 & 15,41 \\
\hline LC & 28 & 10 & 180 & 6,76 & 6,87 & 13,32 & 16,29 \\
\hline BP & 12 & 10 & 150 & 7,48 & 6,92 & 17,86 & 16,59 \\
\hline LC & 20 & 10 & 100 & 6,42 & 6,62 & 15,23 & 15,71 \\
\hline BP & 28 & 10 & 180 & 5,60 & 6,18 & 13,24 & 14,67 \\
\hline LC & 12 & 6 & 150 & 8,16 & 7,12 & 19,39 & 17,04 \\
\hline $\mathrm{BP}$ & 20 & 6 & 100 & 7,48 & 6,92 & 17,71 & 16,12 \\
\hline LC & 28 & 6 & 180 & 6,89 & 6,26 & 16,32 & 17,29 \\
\hline $\mathrm{BP}$ & 12 & 6 & 150 & 8,31 & 6,23 & 19,72 & 17,19 \\
\hline LC & 20 & 6 & 100 & 7,88 & 7,06 & 18,82 & 16,76 \\
\hline BP & 28 & 6 & 180 & 7,12 & 6,27 & 16,82 & 16,11 \\
\hline LC & 12 & 6 & 150 & 8,4 & 6,22 & 19,92 & 17,13 \\
\hline BP & 20 & 6 & 100 & 7,68 & 7,02 & 18,12 & 16,79 \\
\hline LC & 28 & 6 & 180 & 7,06 & 6,76 & 16,65 & 16,14 \\
\hline BP & 12 & 14 & 150 & 8,32 & 7,23 & 19,72 & 17,14 \\
\hline LC & 20 & 14 & 100 & 7,96 & 7,42 & 18,91 & 16,72 \\
\hline BP & 28 & 14 & 180 & 7,56 & 6,04 & 17,72 & 15,23 \\
\hline LC & 12 & 14 & 150 & 8,43 & 7,17 & 20,01 & 16,92 \\
\hline $\mathrm{BP}$ & 20 & 14 & 100 & 7,68 & 6,28 & 18,22 & 14,87 \\
\hline LC & 28 & 14 & 180 & 7,18 & 6,34 & 17,04 & 16,19 \\
\hline BP & 12 & 14 & 150 & 8,11 & 7,19 & 19,32 & 17,04 \\
\hline LC & 20 & 14 & 100 & 7,46 & 6,27 & 17,72 & 16,32 \\
\hline $\mathrm{BP}$ & 28 & 14 & 180 & 7,24 & 6,82 & 17,16 & 16,14 \\
\hline LC & 12 & 10 & 150 & 7,62 & 6,76 & 18,02 & 16,02 \\
\hline $\mathrm{BP}$ & 20 & 10 & 100 & 6,55 & 6,43 & 15,53 & 15,23 \\
\hline LC & 28 & 10 & 180 & 5,59 & 6,89 & 13,28 & 16,31 \\
\hline BP & 12 & 10 & 150 & 7,69 & 6,42 & 18,21 & 15,21 \\
\hline LC & 20 & 10 & 100 & 6,51 & 6,24 & 15,41 & 14,77 \\
\hline BP & 28 & 10 & 180 & 5,37 & 6,42 & 12,71 & 16,01 \\
\hline LC & 12 & 10 & 150 & 7,98 & 6,12 & 18,92 & 16,71 \\
\hline $\mathrm{BP}$ & 20 & 10 & 100 & 6,81 & 6,69 & 16,12 & 15,85 \\
\hline LC & 28 & 10 & 180 & 5,53 & 6,98 & 13,07 & 16,56 \\
\hline BP & 12 & 6 & 150 & 8,56 & 7,23 & 20,32 & 17,13 \\
\hline LC & 20 & 6 & 100 & 7,75 & 7,18 & 18,41 & 17,04 \\
\hline BP & 28 & 6 & 180 & 6,91 & 6,82 & 16,32 & 16,33 \\
\hline LC & 12 & 6 & 150 & 8,73 & 7,45 & 20,71 & 17,68 \\
\hline BP & 20 & 6 & 100 & 7,78 & 7,36 & 18,43 & 17,48 \\
\hline LC & 28 & 6 & 180 & 7,39 & 7,22 & 17,54 & 17,24 \\
\hline BP & 12 & 6 & 150 & 8,68 & 7,23 & 20,68 & 17,25 \\
\hline LC & 20 & 6 & 100 & 8,21 & 7,42 & 19,51 & 17,59 \\
\hline BP & 28 & 6 & 180 & 7,72 & 6,87 & 17,49 & 16,28 \\
\hline LC & 12 & 14 & 150 & 8,73 & 6,67 & 20,71 & 15,47 \\
\hline BP & 20 & 14 & 100 & 8,21 & 6,21 & 19,42 & 14,72 \\
\hline LC & 28 & 14 & 180 & 7,57 & 6,79 & 17,92 & 16,19 \\
\hline BP & 12 & 14 & 150 & 8,4 & 7,18 & 19,96 & 17,01 \\
\hline LC & 20 & 14 & 100 & 7,96 & 6,81 & 18,89 & 16,33 \\
\hline BP & 28 & 14 & 180 & 7,36 & 6,89 & 17,48 & 16,14 \\
\hline LC & 12 & 14 & 150 & 8,58 & 6,76 & 20,31 & 16,02 \\
\hline $\mathrm{BP}$ & 20 & 14 & 100 & 7,62 & 6,28 & 18,18 & 14,71 \\
\hline LC & 28 & 14 & 180 & 7,48 & 7,02 & 17,58 & 16,65 \\
\hline
\end{tabular}


ANOVA based $F$-test was applied to evaluate the significance factor on the surface roughness. This analysis investigates the following for each parameter given in Equation 7 and Equation 8:

$$
\left.\begin{array}{l}
H_{0}: \mu_{1}=\mu_{2}=\ldots=\mu_{\alpha} \\
H_{1}: \mu_{i} \neq \mu_{j} \text { for at least one pair }(i, j)
\end{array}\right\}
$$

The $F$ value is calculated by:

$$
F_{0}=\frac{S S_{A} / \alpha-1}{S S_{E} / N-\alpha}=\frac{M S_{A}}{M S_{E}}
$$

The terms of $(\alpha-1)$ and $(\mathrm{N}-\alpha)$ are the degrees of freedom and the error degrees of freedom for the parameter A, respectively. $M S_{A}$ and $M S_{E}$ are indicated the sum squares of means and errors for the variable $\mathrm{A}$, respectively. The null hypothesis is rejected when the $F_{0}$ is higher than the critical value of $F_{a, a-1, N-a}$, where $\alpha$ is the level of the significance (Antony 2014). (Table 3 and Table 4) displayed the $P$ -value is less than 0,05 showing the model is significant at $95 \%$ confidence level. Value of "prob $>F$ " are lower than 0,05 indicating that the model terms are significant. In this case, the terms of feed rate, cutting speed, material type, sanding direction and grit size resulted in significant factors for stylus and laser measurement equipment.

Table 3. ANOVA for $R_{a}$-Stylus measurement results.

\begin{tabular}{|l|r|r|r|r|}
\hline Source & DF & \multicolumn{1}{|c|}{ SS } & $\boldsymbol{F}$-Value & $\boldsymbol{P}$-Value \\
\hline Model & 39 & 54,4362 & 14,91 & 0,000 \\
\hline Linear & 8 & 37,8121 & 50,50 & 0,000 \\
\hline A & 1 & 0,3616 & 3,86 & 0,043 \\
\hline B & 2 & 2,0603 & 11,01 & 0,000 \\
\hline C & 2 & 11,2362 & 60,02 & 0,000 \\
\hline D & 2 & 0,7518 & 4,02 & 0,022 \\
\hline E & 1 & 13,9347 & 148,88 & 0,000 \\
\hline 2-Way Interactions & 15 & 13,2971 & 9,47 & 0,000 \\
\hline A*B & 2 & 0,1712 & 0,91 & 0,406 \\
\hline A*C & 2 & 0,0441 & 0,24 & 0,791 \\
\hline A*D & 2 & 0,1468 & 0,78 & 0,461 \\
\hline A*E & 1 & 0,0006 & 0,01 & 0,939 \\
\hline B*C & 4 & 1,0796 & 2,88 & 0,029 \\
\hline B*E & 2 & 6,4741 & 34,59 & 0,000 \\
\hline C*E & 2 & 5,0967 & 27,23 & 0,000 \\
\hline $3-W a y$ Interactions & 12 & 2,7572 & 2,45 & 0,010 \\
\hline A*B*C & 4 & 0,3895 & 1,04 & 0,393 \\
\hline A*B*E & 2 & 0,3044 & 1,63 & 0,204 \\
\hline A*C*E & 2 & 0,0053 & 0,03 & 0,972 \\
\hline B*C*E & 4 & 1,8523 & 4,95 & 0,001 \\
\hline 4-Way Interactions & 4 & 0,4126 & 1,10 & 0,363 \\
\hline A*B*C*E & 4 & 0,4126 & 1,10 & 0,363 \\
\hline Error & 68 & 6,3645 & & \\
\hline Lack-of-Fit & 4 & 0,3436 & 0,91 & 0,462 \\
\hline Pure Error & 64 & 6,0210 & & \\
\hline Total & 107 & 60,8008 & & \\
\hline
\end{tabular}

DF: degrees of freedom, SS: Sum of squares, $F: F$-test value and $P$ :error variance

${ }^{a}$ At a given response, parameters belonging to the filled cells are effective within $95 \%$ reliability interval. 
Table 4. ANOVA for $-R_{a}$ Laser measurement results.

\begin{tabular}{|l|r|r|r|r|}
\hline Source & DF & \multicolumn{1}{|c|}{ SS } & $\boldsymbol{F}$-Value & $\boldsymbol{P}$-Value \\
\hline Model & 39 & 305,964 & 33,61 & 0,000 \\
\hline Linear & 8 & 205,660 & 110,15 & 0,000 \\
\hline A & 1 & 2,627 & 11,26 & 0,001 \\
\hline B & 2 & 9,707 & 20,80 & 0,000 \\
\hline C & 2 & 78,894 & 169,01 & 0,000 \\
\hline D & 2 & 1,197 & 2,56 & 0,044 \\
\hline E & 1 & 46,989 & 201,33 & 0,000 \\
\hline 2-Way Interactions & 15 & 77,437 & 22,12 & 0,000 \\
\hline A*B & 2 & 0,168 & 0,36 & 0,699 \\
\hline A*C & 2 & 0,012 & 0,03 & 0,974 \\
\hline A*D & 2 & 0,313 & 0,67 & 0,515 \\
\hline A*E & 1 & 0,406 & 1,74 & 0,192 \\
\hline B*C & 4 & 6,184 & 6,62 & 0,000 \\
\hline B*E & 2 & 38,749 & 83,01 & 0,000 \\
\hline C*E & 2 & 34,771 & 74,49 & 0,000 \\
\hline 3-Way Interactions & 12 & 11,540 & 4,12 & 0,000 \\
\hline A*B*C & 4 & 3,021 & 3,24 & 0,017 \\
\hline A*B*E & 2 & 1,392 & 2,98 & 0,057 \\
\hline A*C*E & 2 & 0,059 & 0,13 & 0,881 \\
\hline B*C*E & 4 & 5,956 & 6,38 & 0,000 \\
\hline 4-Way Interactions & 4 & 3,210 & 3,44 & 0,013 \\
\hline A*B*C*E & 4 & 3,210 & 3,44 & 0,013 \\
\hline Error & 68 & 15,871 & & \\
\hline Lack-of-Fit & 4 & 0,688 & 0,72 & 0,578 \\
\hline Pure Error & 64 & 15,183 & & \\
\hline Total & 107 & 321,835 & & \\
\hline & S & & & \\
\hline
\end{tabular}

DF: degrees of freedom, SS: Sum of squares, $F: F$-test value and $P$ :error variance

${ }^{a}$ At a given response, parameters belonging to the filled cells are effective within $95 \%$ reliability interval.

\section{Evaluation of the models}

The normal probability plot of the residuals and residuals versus the predicted for $R_{a}$ are shown in (Figure 3). Evaluating on the normal probability plots (NPP) are shown in Figure 3a, Figure 3b) depicts that the residuals generally fall on a straight line implying that the errors are distributed normally. In addition to these Figure 3c, Figure 3d) show that the residuals versus the fitted values for the surface roughness data. As result of the residuals no unusual structure is apparent. This implies that the models proposed are adequate and there is no reason to suspect any violation of the independence or constant variance assumption (Montgomery 1997). 


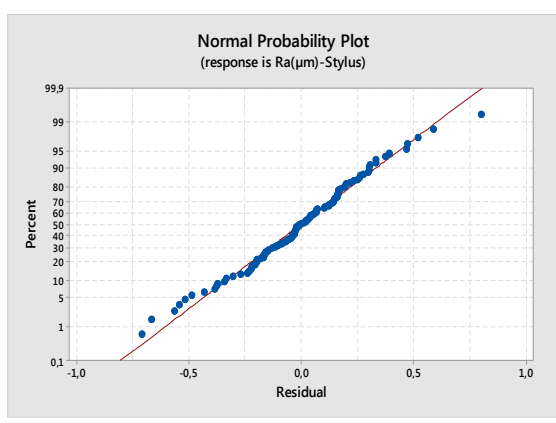

(a)

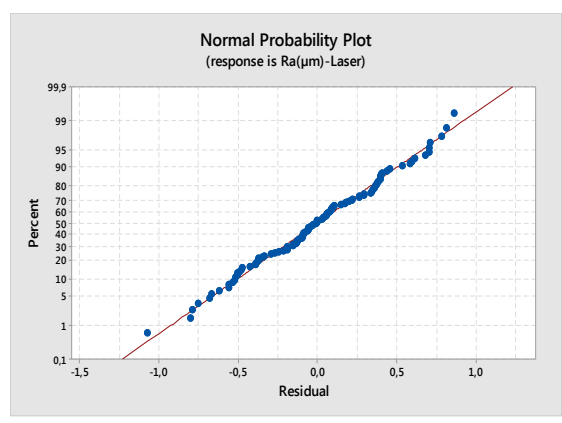

(b)

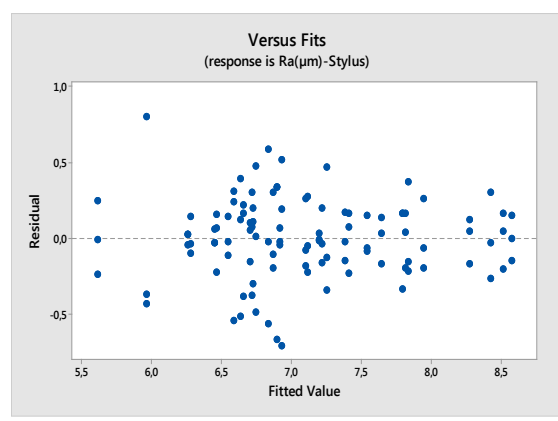

(c)

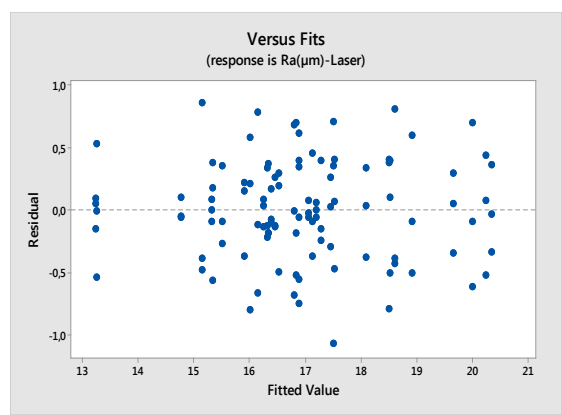

(d)

Figure 3. (a-b) NPP of residuals and (c-d) plot of residuals fitted for $R_{a}-$ Stylus and Laser results.

\section{Parameter prediction by using ANN}

According to the results obtained from the analysis of variance, the sanding parameters of grit size, feed rate, cutting speed, material type and sanding directions were found as effective factors on surface quality for laser and stylus type equipment. In this reason, these variables were selected as input parameters while the surface roughness was selected as output parameter for ANN. The gathered data making of 108 was used as 76 samples for the training, 16 samples for the validation and 16 samples for the testing. The accuracy of models was performed by using correlation coefficient $\left(\mathrm{R}^{2}\right)$ and MSE values. These results were given in (Table 5).

Table 5. ANN performance results.

\begin{tabular}{|l|l|l|l|}
\hline & Samples & MSE & $\mathbf{R}^{2}$ \\
\hline Training & $76(76)$ & $1,45(8,59)$ & $0,975(0,945)$ \\
\hline Validation & $16(16)$ & $7,44(1,38)$ & $0,945(0,924)$ \\
\hline Testing & $16(16)$ & $6,25(1,97)$ & $0,906(0,878)$ \\
\hline
\end{tabular}

Figure 4 displays the relationship between the measured and predicted values for training, validation and testing data. (Figure $4 \mathrm{a}$ ) displays $\mathrm{R}^{2}$ values for training, validation and testing data sets in predicting stylus measure of 0,9450;0,92462 and 0,87836 respectively. (Figure 4b) displays $\mathrm{R}^{2}$ values for training, validation and testing data sets in predicting laser measuring of 0,$97528 ; 0,94573$ and 0,90692 respectively. 

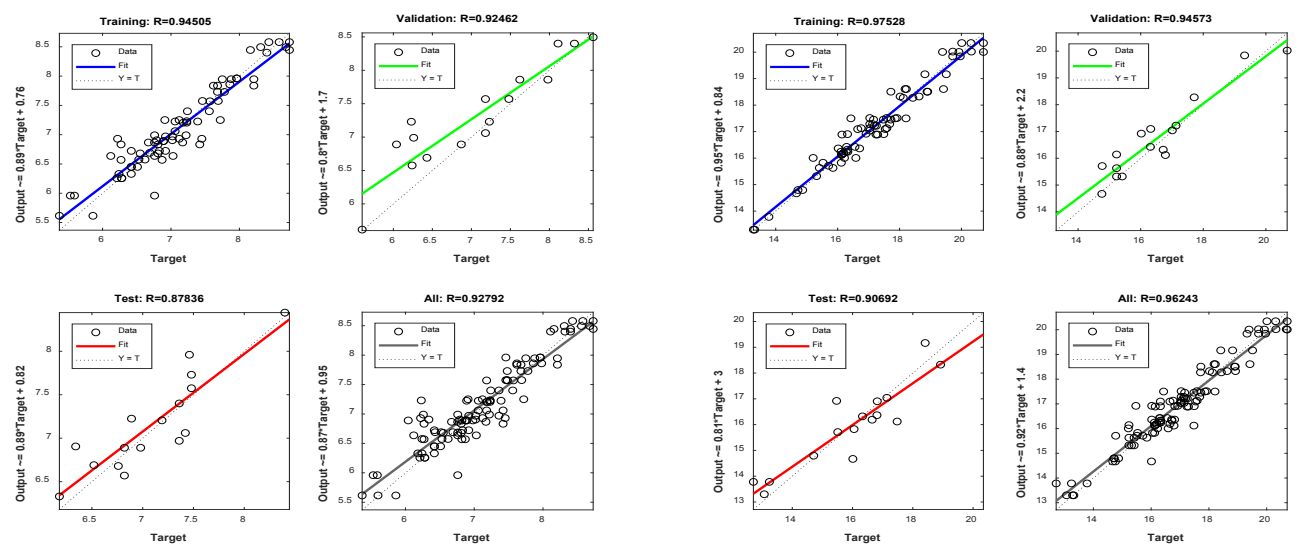

(a)

(b)

Figure 4. Training, validation and testing results for (a) stylus and (b) laser type equipment.

According to Figure $4, \mathrm{R}^{2}$ values are close to 1 for training, validation and testing data. It means that there is a good relationship between the measured values and the predicted values. Moreover, MSE values of training, validation and testing parameters were found as 1,45; 7,44 and 6,25 for laser-based measurement system, respectively, whereas MSE values of training, validation and testing parameters were computed as 8,$59 ; 1,38$ and 1,97 for stylus-based measurement equipment, respectively. These results were used to evaluate the performance for predicting models. Because of the high values of $\mathrm{R}^{2}$ and the low level of errors, these models were satisfactory. A value of $\mathrm{R}^{2}$ obtained from laser-based measurement was better than stylus type equipment. (Figure 5 and Figure 6) showed the relationship between the measured and predicted values for laser and stylus type equipment. Moreover, the MAPE values for all data are given in (Figure 5 and Figure 6). MAPE values for laser and stylus measurement equipment were computed as 2,405\% and 3,766 \%, respectively. MAPE values for laser measurement equipment lower than stylus type equipment.

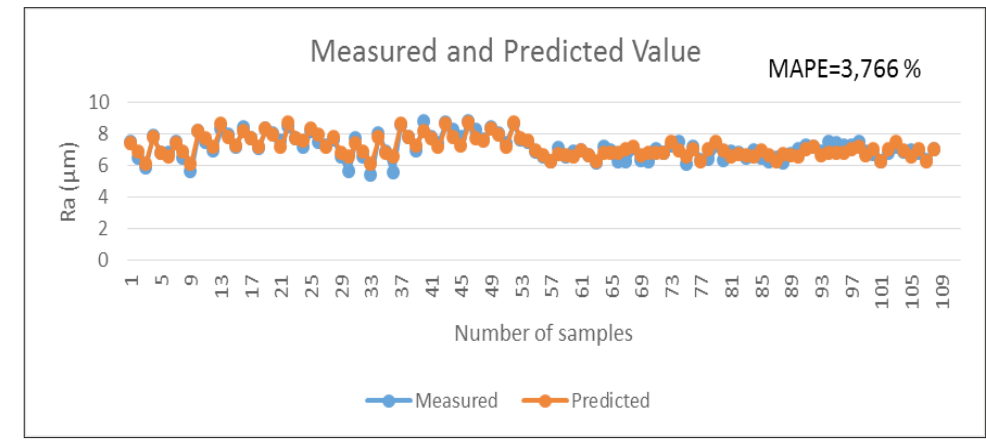

Figure 5. The relationship between the measured and predicted values for laser measurement.

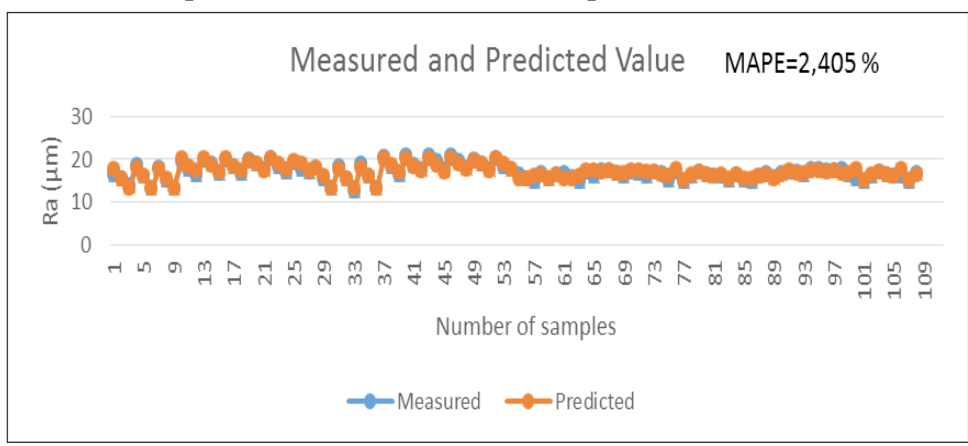

Figure 6. The relationship between the measured and predicted values for stylus measurement. 


\section{CONCLUSIONS}

In this study, prediction method of ANN on the two wood materials was carried out for sanding process. Two different measurements equipment namely, stylus and laser were used to determine the wood surface quality. The results are as follows:

(1) The results were analyzed using the full factorial design based ANOVA method. According to results, the grit size, feed rate, cutting speed, sanding direction and material type were the effective factor on the roughness for two measurement equipment.

(2) The surface roughness values were evaluated by two different methods. According to results, both methods were found as suitable to evaluate the wood surface roughness. As stylus type equipment contacted with the wood surface, it can give some restricted results than the laser sensor. In addition to these, the laser sensor can measure the pick value and do not contact the material, it was more suitable for automation systems in order to evaluate the wood surface quality.

(3) Two models were developed using ANN to formulate the input parameters such as feed rate, grit size, cutting speed, material type and sanding directions to the $R_{a}$.

(4) ANN models were performed using MAPE and $R^{2}$. MAPE values for laser and stylus equipment were found as $2,405 \%$ and $3,766 \%$ respectively. $R^{2}$ values were determined as $96,2 \%$ and $92,7 \%$ for laser and stylus measurement equipment, respectively. ANN model for laser-based evaluated system was more accurate than stylus type equipment. The reason of this situation, laser system was gathered to more data than stylus type equipment.

(5) As a result, the values of high $\mathrm{R}^{2}$ and the low MAPE showed that the proposed models can be successfully used to predict the $R_{\mathrm{a}}$ values.

\section{ACKNOWLEDGMENTS}

This work was supported by Scientific Research Projects Coordination Unit of Istanbul University. Project number 7863.

\section{REFERENCES}

Antony, J.2014. Design of experiments for engineers and scientists. Second ed., Elservier, London.

Carrano, A.L.; Taylor, J.B.; Lemaster, R. 2002. Parametric characterization of peripheral sanding. Forest Products Journal 52(9):44-50.

Cool, J.; Hernández, R.E. 2011. Improving the sanding process of black spruce wood for surface quality and water-based coating adhesion. Forest Products Journal 61: 372-380.

Gurau, L.; Csiha, C.; Mansfield-Williams, H. 2015. Processing roughness of sanded beech surfaces. European Journal of Wood and Wood Products 73: 395-398.

Gurau, L.; Mansfield-Williams, H.; Irle, M. 2013. The influence of measuring resolution on the subsequent roughness parameters of sanded wood surfaces. European Journal of Wood and Wood Products 71(1):5-11.

Hazir, E. 2013. A Modeling Study to Evaluate the Quality of Wood Surface. Msc. Thesis, Istanbul University, Istanbul, Turkey. 
Hazir, E.; Koc, K.H.; Hiziroglu, S. 2017. Optimization of sanding parameters using response surface methodology. Maderas-Cienc Tecnol 19(4):407-416.

Hiziroglu, S.; Suzuki, S. 2007. Evaluation of surface roughness of commercially manufactured particleboard and medium density fiberboard in Japan. Journal of Materials Processing Technology $184: 436-440$.

Hiziroglu, S.; Zhong, Z.W.; Ong, W.K. 2014. Evaluation of bonding strength of pine, oak and nyatoh wood species related to their surface roughness. Measurement 49:397-400.

International Organization for Standardization. 1997. Geometrical product specifications (GPS) surface texture: profile method-terms, definitions, and surface texture profile method terms, definitions and surface texture parameters. ISO 4287. 1997

Jain, V.; Raj, T. 2017. Tool life management of unmanned production system based on surface roughness by ANFIS. International Journal of Systems Assurance Engineering and Management $8(2): 458-467$

Karazi, S.M.; Issa, A.; Brabazan, D. 2009. Comparison of ANN and DoE for the prediction of laser-machined micro-channel dimensions. Optics and Lasers in Engineering 47:956-964.

Koc, H.; Erdinler, E.S.; Hazir, E.; Oztürk, E. 2017. Effect of CNC application parameters on wooden surface quality. Measurement 107:12-18.

Laina, R.; Lobera, A.S.; Villasante, A.; Espi, P.L.; Rojas, J.A.M.; Alpuente, J.; Montero, R.S.; Vignote, Santiago. 2017. Effect of the anatomical structure, wood properties and machining conditions on surface roughness of wood. Maderas-Cienc Tecnol 19(2):203-212.

Landry, V.; Blanchet, P. 2012. Surface preparation of wood for application of waterborne coatings. Forest Products Journal 62(2):39-45. 790.

Magoss, E. 2015. Evaluating of the surface roughness of sanded wood. Wood Research 60(5):783-

Mahes, G.; Muthu, S.; Devadasan, S.R. 2015. Prediction of surface roughness of end milling operation using genetic algorithm. The International Journal of Advanced Manufacturing Technology 77:369-381.

Montgomery, D.C. 1997. Design and analysis of experiment. John Wiley Publishing. New York.

Ozsahin, S.; Aydin, I. 2014. Prediction of the optimum veneer drying temperature for good bonding in plywood manufacturing by means of artificial neural network. Wood Science and Technology 48:5970 .

Ramananantoandro, T.; Eyma, F.; Belloncle, C.; Rince, S.; Irle, M. 2017. Effect of machining parameters on raised grain occurring after the application of water-based finishes. European Journal of Wood and Wood Products 76(4): 1323-1333

Richter, K.; Feist, W. C.; Knaebe, M. T. 1995. The effect of surface roughness on the performance of finishes. Part 1: roughness characterization and stain performance. Forest Products Journal 45(7/8):91-96.

Sandak, J.; Tanaka, C. 2003. Evaluation of surface smoothness by laser displacement sensor 1: Effect of wood species. Journal of Wood Science 49(4):305-311.

Scrinzi, E.; Rossi, S.; Deflorian, F.; Zanella, C. 2011. Evaluation of aesthetic durability of 701 
waterborne polyurethane coatings applied on wood for interior applications. Progress in Organic Coatings 72(1):81-87.

Sogutlu, C.; Nzokou, P.; Koc, Ismail.; Tutgun, R.; Döngeș, N. 2016. The effect of surface roughness on varnish adhesion strength of wood materials. Journal of Coating Technology and Research 13(5):863-870.

Tan, P.L.; Sharif, S.; Sudin, I. 2012. Roughness models for sanded wood surfaces. Wood Science and Technology 46:129-142.

Tiryaki, S.; Malkocoglu, A.; Ozsahin, S. 2014. Using artificial neural networks for modeling surface roughness of wood in machining process. Construction and Building Materials 66:329-335.

Ugulino, B.; Hernandez, R.E. 2016. Analysis of sanding parameters on surface properties and coating performance of red oak wood. Wood Material Science \& Engineering 1-9.

Zhong, Z.W.; Hiziroglu, S.; Chan, C.T. M. 2013. Measurement of the surface roughness of wood based materials used in furniture manufacture. Measurement 46:1482-1487. 